Supplement of Biogeosciences, 12, 7423-7434, 2015

http://www.biogeosciences.net/12/7423/2015/

doi:10.5194/bg-12-7423-2015-supplement

(C) Author(s) 2015. CC Attribution 3.0 License.

(c) (i)

Supplement of

\title{
Quantifying wind and pressure effects on trace gas fluxes across the soil- atmosphere interface
}

\section{K. R. Redeker et al.}

Correspondence to: K. R. Redeker (kelly.redeker@york.ac.uk)

The copyright of individual parts of the supplement might differ from the CC-BY 3.0 licence. 


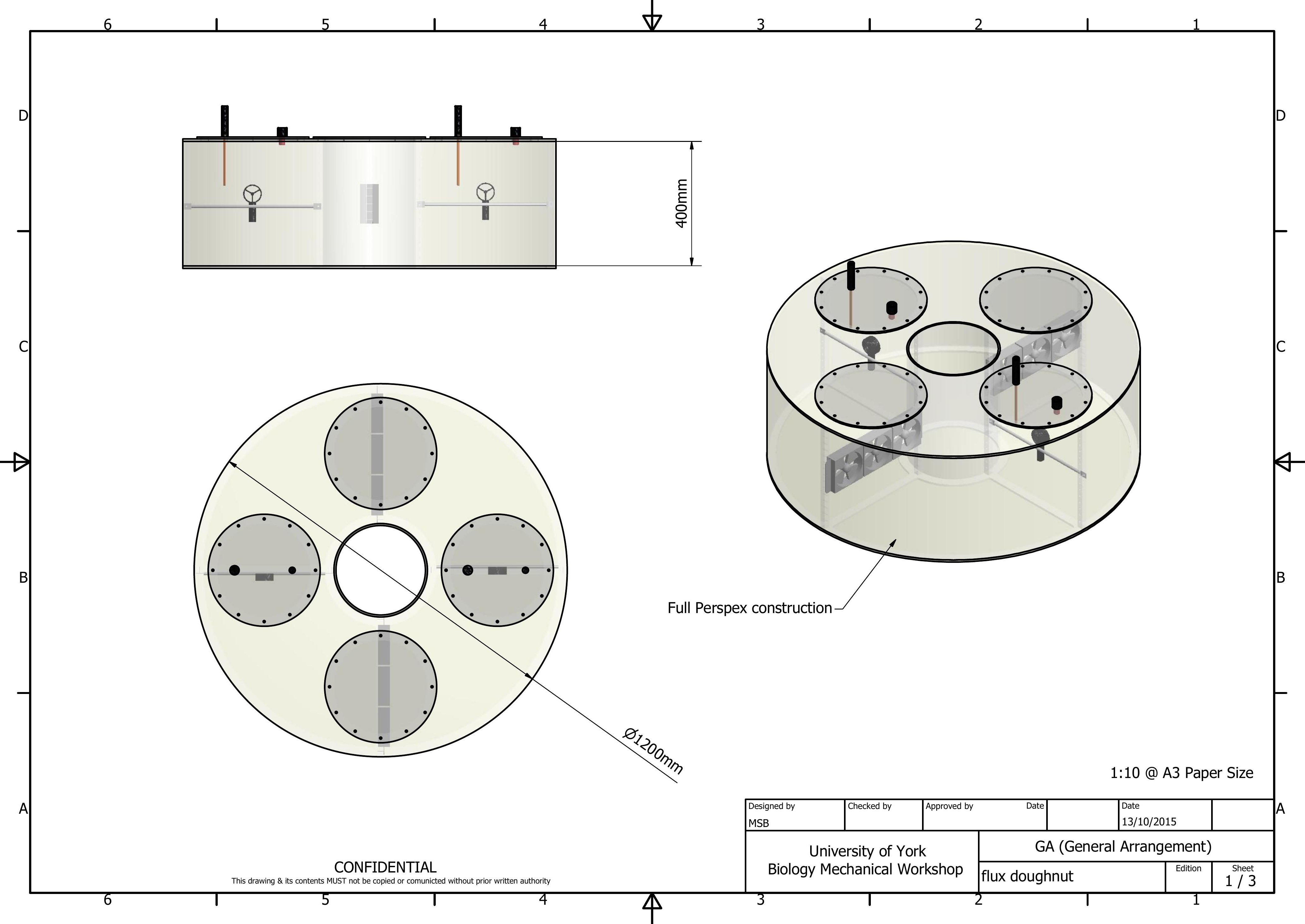




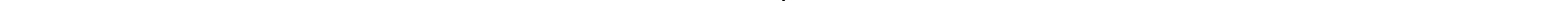



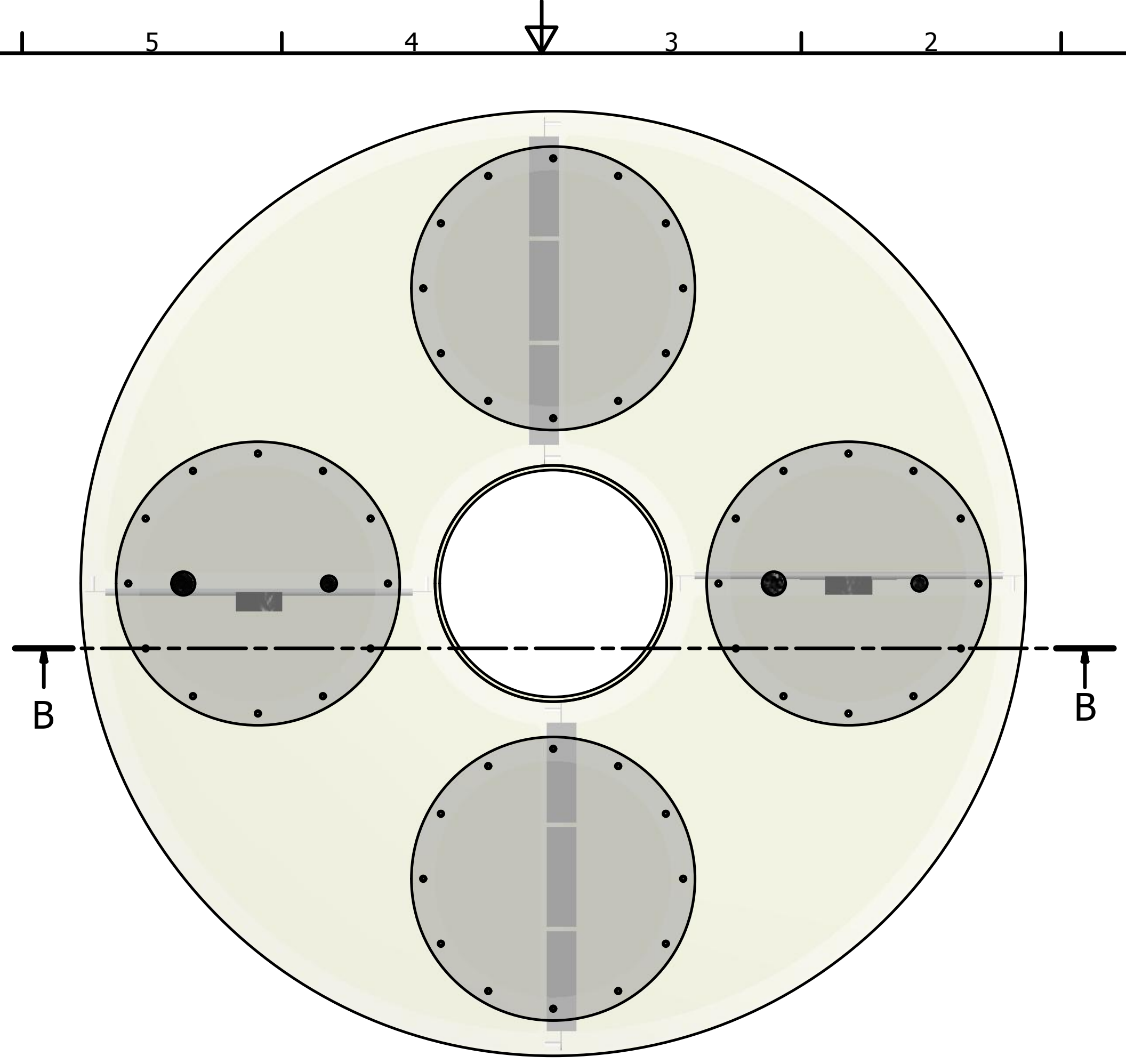

D

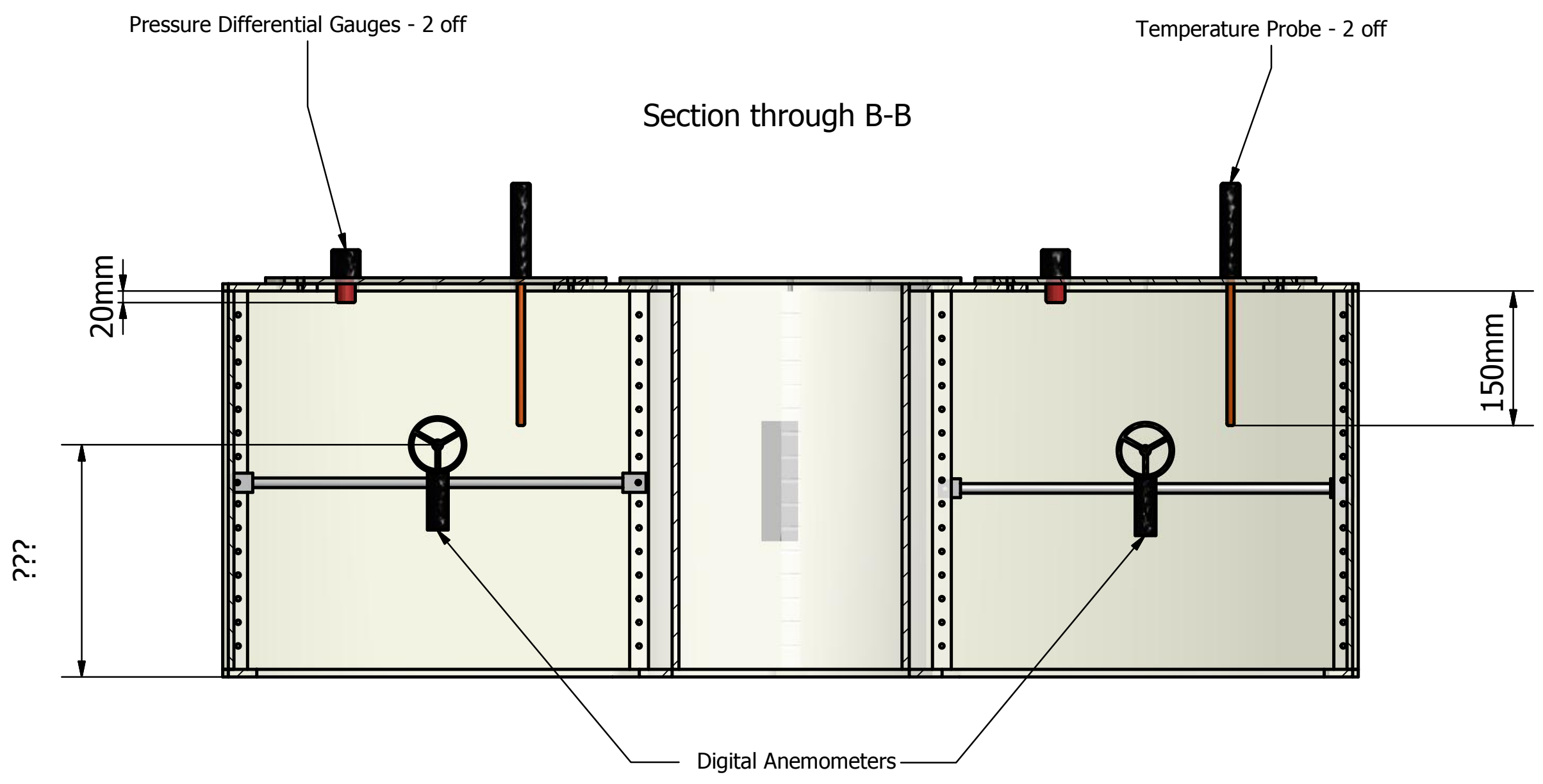

B

1.5:10 @ A3 Paper Size

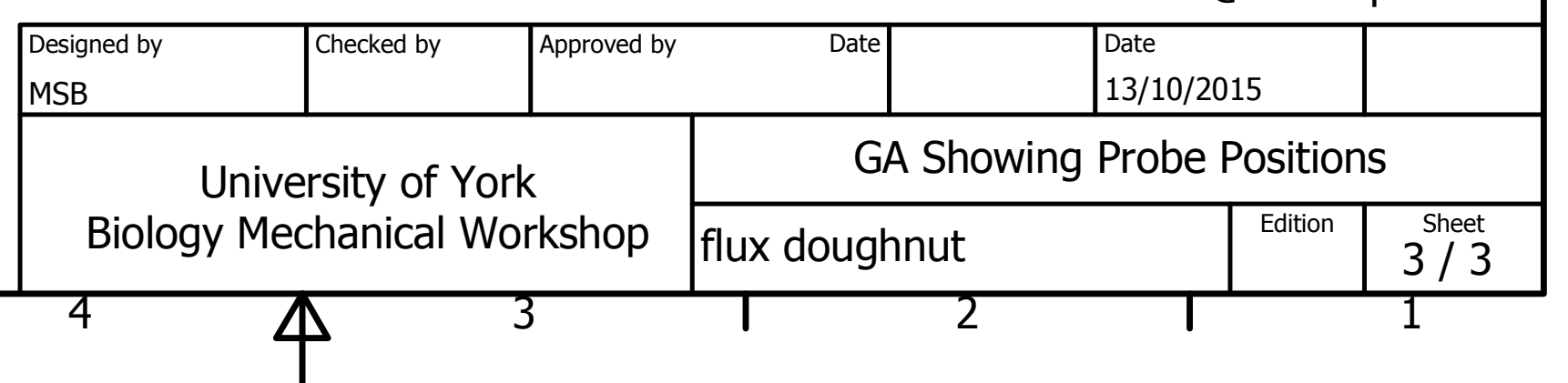

